\title{
Human T lymphotropic virus type I associated myelopathy with pulmonary and cutaneous lesions
}

H Kuwabara, J Katanaka, M Nagai, H Uda, W Hojo, A Yamada, H Miki, H Takeuchi, K Teranishi, K Matsuda, Y Uchida, K Nakashima, M Sasaki, R Sepp

\begin{abstract}
A necropsy case of human $T$ lymphotropic virus I (HTLV-I) associated myelopathy (HAM) in a 64 year old man with serological and genetical confirmation of HTLV-I infection is reported. The spinal cord, lung, and skin were mainly affected. Severe degeneration had occurred in the spinal cord, not only in the lateral columns but also in the anterior and posterior columns. The degenerate lesions showed proliferation of capillaries, loss of myelin and axon, and perivascular and parenchymal infiltration with $T$ lymphocytes and foamy macrophages in the white matter. $T$ lymphocytes had infiltrated the lung and there was vascular proliferation in the peribronchus. OPD4 positive cells predominated in the lung. The patient also had erythrodermia where dense and bandlike HTLV-I infected lymphoid cell infiltration was observed, with mild atypia and epidermotropism. HTLV-I may cause multiorganic inflammatory disorders, although the definitive role of HTLV-I in the pathogenesis is still unknown.
\end{abstract}

$(F$ Clin Pathol 1993;46:273-275)

Department of

Pathology, Kagawa

Medical School,

Kagawa

H Kuwabara

H Uda

R Sepp

Department of

Internal Medicine,

Kagawa Medical

School, Kagawa

J Katanaka

M Nagai

W Hojo

A Yamada

H Miki

H Takeuchi

K Teranishi

K Matsuda

Y Uchida

Department of

Dermatology, Kagawa

Medical School,

Kagawa

K Nakashima

M Sasaki

Correspondence to:

Dr H Kuwabara, Second

Department of Pathology,

Department of Pathology,

1750-1, Miki-cho, Kita-gun,

Kagawa, 761-07, Japan

Accepted for publication

29 September 1992
HTLV-I is the first isolate of human retroviruses and its aetiological role in adult $\mathrm{T}$ cell leukaemia (ATL) has been firmly established. ${ }^{1}$ HTLV-I has also been reported to be implicated in the pathogenesis of certain types of chronic progressive myelopathy. The disease is prevalent in areas endemic for HTLV-I infection, such as Jamaica, Colombia, Martinique and the Seychelles, where it is known as tropical spastic paraparesis (TSP), ${ }^{2}$ and in the southern part of Japan as HTLV-I associated myelopathy (HAM) ${ }^{3}$ It is now agreed that TSP and HAM are the same disease. Moreover, an association between HTLV-I and bronchopneumonopathy has recently been suggested, although the precise mechanism is not clear. ${ }^{45}$

As far as we know, this is the first necropsy case of HAM with pulmonary and cutaneous lesions.

\section{Case report}

A 64 year old Japanese man, from southern Japan, had received blood transfusions at surgery for A-C bypass in 1985 when he was
57 years old. A few months after surgery, he noticed erythema on the chest and limbs. In 1990, muscular weakness of the lower extremities set in and bladder and rectal dysfunction developed. The weakness increased slowly but steadily and spread to the upper extremities, and he could not walk without a Zimmer frame. In June 1991, he was referred to the department of neurology of our hospital. On admission, neurological examinations disclosed spastic gait, weakness, and atrophy of the arm and leg muscles, and hyperreflexia in the extremities with bilateral Babinski's sign. Deep sensation, including position and vibration sense, and superficial sensation were decreased. The cranial nerves were intact. A computed tomogram of the brain was normal except for mild subdural effusion.

The peripheral blood leucocyte count was $13.6 \times 10^{3} / \mu \mathrm{l}$ ) with $54.0 \%$ lymphocytes. Morphologically, atypical lymphocytes were less than $1 \%$. Examination of the lymphocyte differential showed $1 \%$ of B cells and $98 \%$ of $\mathrm{T}$ cells $(71.0 \% \mathrm{CD} 4$ positive, $31.0 \% \mathrm{CD} 8$ positive, and a CD4:CD8 positive ratio of $2 \cdot 3$ ). A bone marrow aspirate showed no abnormal findings. The cerebrospinal fluid (CSF) contained 16 mononuclear cells $/ \mu \mathrm{l}$ with some apparent flower-like cells, $32 \mathrm{mg} / \mathrm{dl}$ of protein and $50 \mathrm{mg} / \mathrm{dl}$ of sugar.

Serological tests for syphilis and HIV-I yielded negative results. Antibodies to HTLV-I in the serum and CSF were positive at titres of more than $256 x$ and $256 x$, respectively, by the particle agglutination test (Fuji Rebio). Proviral DNA of HTLV-I in peripheral mononuclear cells showed polyclonal integration by Southern blot analysis. A chest $x$-ray showed diffuse fine reticular shadows in both lung fields. Treatment with steroids initially improved spasticity and muscle power to some extent, but erythema had developed over the whole body. A biopsy specimen of the skin of the right forearm lesion showed dense and bandlike lymphoid cell infiltration in the upper dermis. These lymphoid cells showed mild atypia and epidermotropism but were not convoluted. Though HTLV-I associated lymphoma was strongly suspected, the integration of proviral DNA of HTLV-I in this lesion showed a polyclonal pattern by Southern blot analysis. The skin lesions were treated by painting with steroids.

In November of 1991, dyspnoea developed and in February 1992, emergency surgery for perforation of descending colon was performed. One month later, bleeding of the gastrointestinal tract set in and sclerotherapy was 


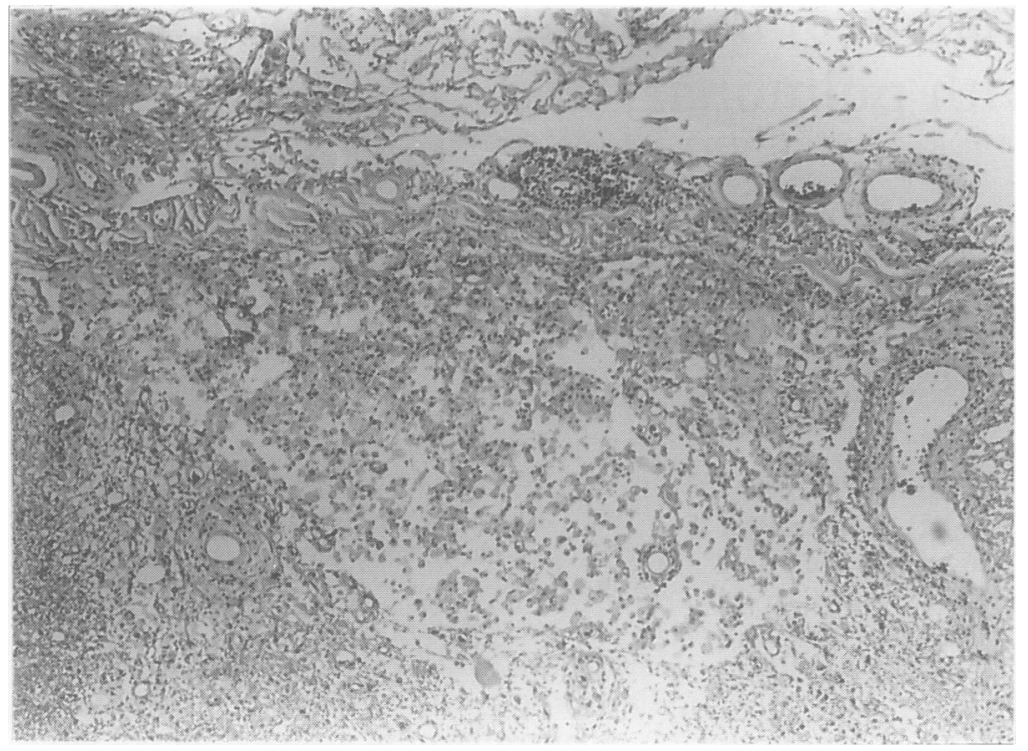

Figure 1 Lymphocytic perivascular cuff and infiltration of foamy macrophages in the posterior columns of the upper thoracic cord.

performed. In spite of supportive treatment his condition deteriorated, and the patient died of congestive heart failure in March, at the age of 64 , two years after the onset of the disease.

\section{Necropsy findings}

The specimens were fixed in $10 \%$ formalin, and paraffin wax sections were stained with haematoxylin and eosin and by the method of Klüver and Barrera. For immunohistochemical analysis, using the avidin-biotin complex method, preparations were made from $3 \mu \mathrm{m}$ thick paraffin wax sections and the following monoclonal antibodies were used: MT1 and UCHL1 for T cells; L26 for B cells; and OPD4 for helper/inducer $\mathrm{T}$ cells. ${ }^{6}$ All antibodies were purchased from Dakopatts.

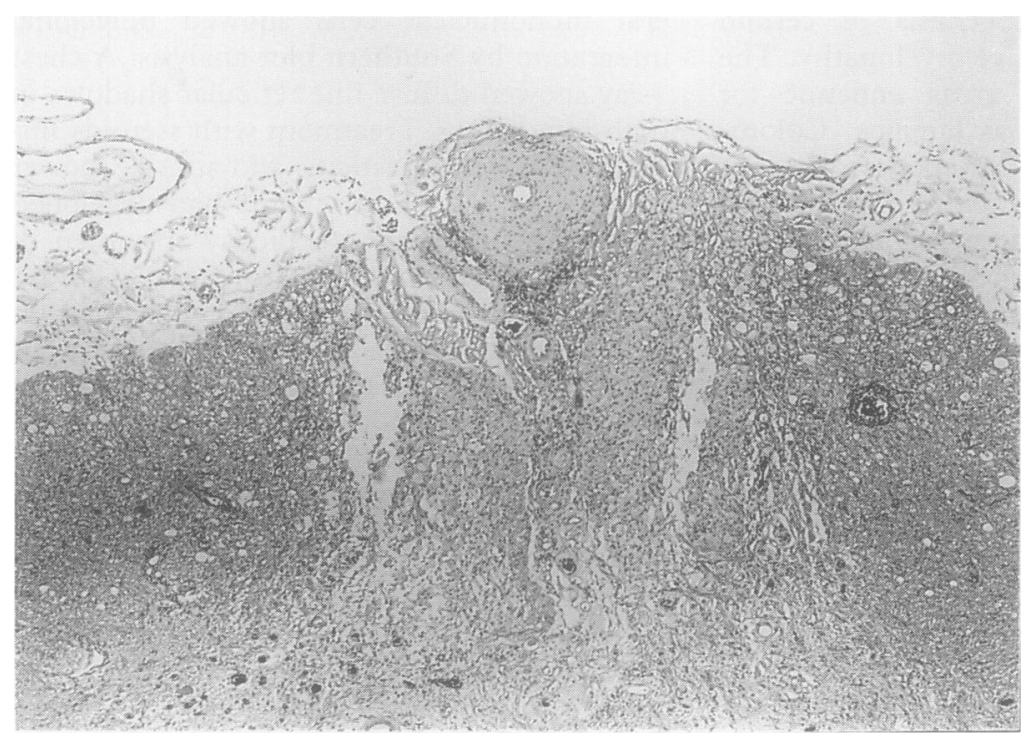

Figure 2 Anterior spinal artery shows thickening of media associated with periadventitial infiltration with lymphocytes
CENTRAL NERVOUS SYSTEM

The spinal cord was grossly atrophic, most obviously at the thoracic level. Microscopically, the lateral columns had degenerated in the lower thoracic cord, and symmetrical myelin and axon were lacking. Only a few inflammatory cells were observed in this lesion. On the other hand, in the middle and upper thoracic cord, the anterior and posterior (Goll's tract and the medial border of the bilateral Burdach's tract) columns had degenerated. These lesions contained lymphocytic perivascular cuffs in the white matter, where loss of axon and myelin along with infiltration of foamy macrophages and proliferation of capillaries were observed (fig 1). The anterior spinal artery showed thickening of the media and periadventitial infiltration with lymphocytes (fig 2). Almost all the perivascular and parenchymal lymphocytes in the spinal cord were positive for $\mathrm{T}$ cell markers (MT1, UCHL 1). About $15 \%-20 \%$ of these $\mathrm{T}$ cells were positive for OPD4. The brain weighed $1260 \mathrm{~g}$ and showed no remarkable changes. There were no intranuclear or intracytoplasmic inclusion bodies or multinucleated giant cells in any part of the brain or the spinal cord. No atypical lymphocytes characteristic of ATL cells were observed in the spinal cord and the brain.

LUNG

The lung showed infiltration of lymphocytes and vascular proliferation in the peribronchus (fig 3). Almost all of the infiltrating lymphocytes were positive for $\mathrm{T}$ cell markers (MT1 and UCHL1) with a predominance of OPD4 positive cells. No atypical lymphocytes were observed.

\section{SKIN}

Specimens were taken from the erythema from the chest and lower limbs. These specimens showed capillary proliferation and perivascular infiltrate composed of OPD4 positive $T$ lymphocytes. The upper dermis showed pronounced oedema. Compared with the findings of the previous biopsy specimen, the infiltrating lymphocytes were noticeably fewer and atypical lymphocytic infiltration in the dermis was not seen, probably because of steroid treatment.

\section{Discussion}

A new clinical and epidemiological entity for chronic progressive myelopathy, termed HAM, was proposed by Osame et al in $1986 .{ }^{2}$ The main clinical features are spastic paraparesis with pyramidal signs, and mild sensory and sphincter disturbances. In these patients, antibodies to HTLV-I are detected in serum and CSF, suggesting that HTLV-I might have a role in the pathogenesis of HAM. Usually myelography and computed tomography of the brain show normal findings. Treatment with corticosteroids is partially effective. The present case was clinically consistent with HAM. He might have been infected with HTLV-I as a result of blood 


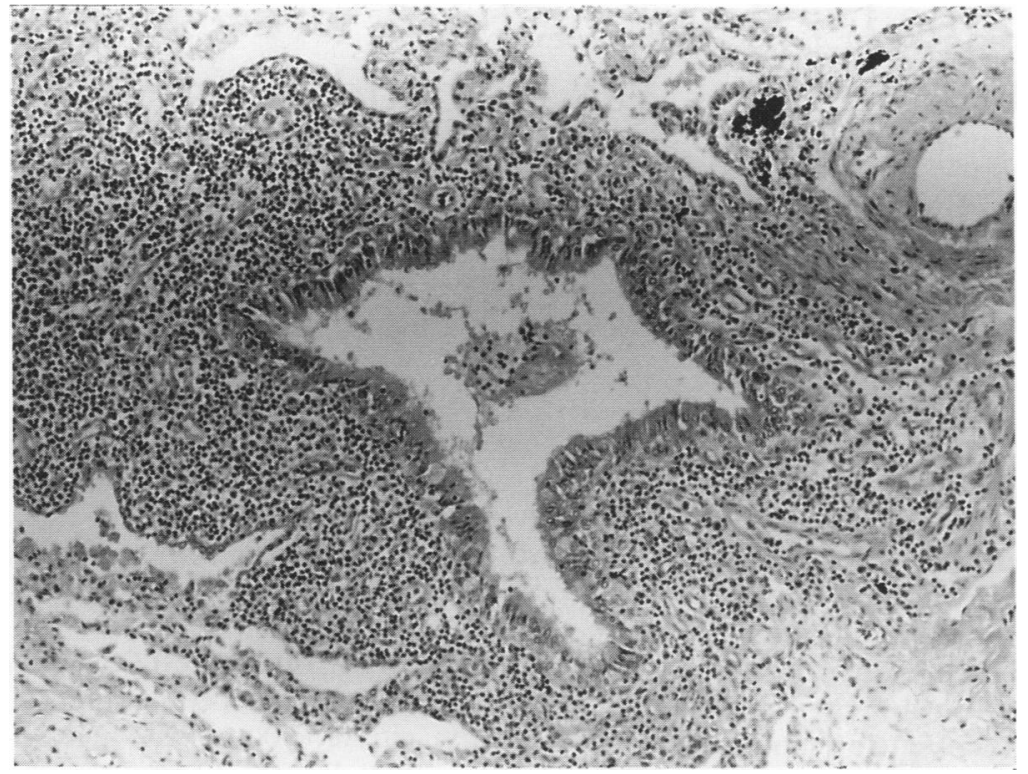

Figure 3 Lymphocytic infiltration in the peribronchus of the lung.

transfusion at A-C bypass operation, because none of his family so far examined has been positive for HTLV-I. Previous pathological findings in HAM have included almost symmetrical and severe degeneration of the spinal long tracts, accompanied by pronounced parenchymal exudation of lymphocytes and monocytes in the lateral columns and at the lower thoracic cord. ${ }^{7}$ In our case loss of myelin and axon were seen in the lower thoracic cord, but few inflammatory cells were present. On the other hand, the middle and upper thoracic cords presented perivascular cuffing and many foamy macrophages. In general, the older lesions were always in the lower thoracic cord, so the absence of inflammatory reactions in this lesion did not seem surprising. On the other hand, the lesions in the upper thoracic segments seemed to be relatively new.

Interestingly, in addition to the typical clinical and pathological findings for HAM, our patient had cutaneous and pulmonary lesions. A biopsy specimen of erythema lesions showed dense and bandlike lymphoid cell infiltration with mild atypia and epidermotropism. From these observations, we could not exclude the possibility of HTLV-I-associated lymphoma, but Southern blot analysis using peripheral mononuclear cells and skin lesions showed polyclonal integration for HTLV-I proviral DNA.

On the other hand, the lung was infiltrated with lymphocytes with a predominance of OPD4 positive cells and vascular proliferation in the peribronchus. Recently pulmonary disease in a patient with HAM has been reported. ${ }^{4}$ In this lesion a chest $x$-ray picture occasionally revealed micronodular infiltrates in both lower lung fields, and specimens obtained by transbronchial lung biopsy showed lympocytic infiltration in the alveolar and bronchial structures. These lymphocytes mainly consisted of $\mathrm{T}$ cells which did not resemble blast cells morphologically. Maruyama et al reported pulmonary disease not only in patients with HAM but also among healthy HTLV-I carriers without any other diseases. They found that the HTLV-I antibody was positive in the bronchoalveolar lavage fluid (BAL). ${ }^{5}$ In our case, most of the peribronchial lymphocytes were positive for $T$ cell markers (MT1, UCHL1) with a predominance of morphological normal OPD4 positive cells. These findings support the conclusion that our case was compatible with HTLV-I associated bronchopneumonopathy, although HTLV-I antibody in BAL was not examined.

This case confirms that HTLV-I causes multiorganic inflammatory disorders, although the definitive role of HTLV-I in the pathogenesis is still unknown.

1 Yoshida M, Seiki M, Yamaguchi K, et al. Monoclonal integration of human $\mathrm{T}$-cell leukemia provirus in all primary tumors of adult $\mathrm{T}$-cell leukemia suggests causative role of human T-cell leukemia virus in the disease. Proc Natl Acad Sci USA 1984;81:2534-7.

2 Gessain A, Francis H, Sonan T, et al. HTLV-I and tropical spastic paraparesis is in Africa. Lancet 1986;ii:698.

3 Osame M, Usuku K, Izumo S, et al. HTLV-I associated myelopathy, a new clinical entity. Lancet 1986;i:1031-2. Sugimoto M, Nakashima H, Watanabe S, et al. T-lym phocyte alveolitis in HTLV-I-associated myelopathy. Lancet 1987; ii: 1220

5 Maruyama I, Tihara J, Sakashita I, et al. HTLV-1 associated bronchopneumonopathy-A new clinical entity? Am Rev Respir Dis 1988;137:46.

6 Yoshino $\mathrm{T}$, Mukuzono $\mathrm{H}$, Aoki $\mathrm{H}$, et al. A novel monoclonal antibody (OPD4) recognizing a helper/inducer $T$ cell subset. Its application to paraffin-embedded tissues. Am f Pathol 1989;134:1339-46.

7 Iwasaki Y. Pathology of chronic myelopathy associated with HTLV-I infection (HAM/TSP). F Neurol Sci 1990; 96:103-23. 